\title{
Calidad bacteriológica del agua Vereda El Charco, San Miguel de Sema, Boyacá- Colombia.
}

\author{
Bacteriological water quality Vereda El Charco, San Miguel de Sema, \\ Boyacá, Colombia.
}

Ávila de Navia Sara Lilia', Estupiñán-Torres Sandra Mónica¹, Díaz González Liliana²

\section{Resumen}

Objetivo. Determinar la calidad bacteriológica del agua de la red de distribución del acueducto veredal El Charco ubicado en el municipio de San Miguel de Sema, Boyacá - Colombia, mediante los indicadores microbiológicos coliformes totales, Escherichia coli y Enterococcus. Métodos. Se tomaron doce muestras de agua de diferentes puntos de la red de distribución del acueducto. El recuento de microorganismos se realizó por el método de filtración de membrana siguiendo el Standard Methods. Resultados. En las muestras analizadas, se determinó presencia de coliformes totales y Enterococcus. Se evidenció que las muestras analizadas en el acueducto veredal superan las $0 \mathrm{UFC} / 100 \mathrm{~mL}$ en los indicadores Coliformes totales y Enterococcus, por tal razón no es apta para el consumo humano.

Palabras clave: calidad del agua, método de filtración por membrana, coliformes.

\section{Abstract}

Objective. To determine the bacteriological quality of the water of the distribution network of the aqueduct El Charco located in the municipality of San Miguel of Sema, Boyacá - Colombia, were use the microbiological indicators total coliforms, Escherichia coli and Enterococcus. Methods. There took twelve water samples of different points of the distribution network of the aqueduct. The count of microorganisms was realized by membrane filtration following the Standard Methods. Results. There was demonstrated that the samples analyzed in the aqueduct veredal overcome the $0 \mathrm{CFU} / 100 \mathrm{~mL}$ of total Coliforms and Enterococcus, for such a reason it is not suitable for the human consumption.

Keywords: water quality, membrane filtration method, coliforms.

\footnotetext{
'Grupo Calidad de Aguas, Universidad Colegio Mayor de Cundinamarca

2Egresada Universidad Colegio Mayor de Cundinamarca

Correspondencia: sestupinan@unicolmayor.edu.co

Monica Estupiñan Torres Orcid: 0000-0002-6937-4567, Sara Ávila de Navia Orcid: 0000-0002-6188-0086

Recibido: XXXXXXXX Aceptado: XXXXXXX
} 


\section{Introducción}

San Miguel de Sema está ubicado al occidente del departamento de Boyacá - Colombia, cuenta con 7 veredas: Sabaneca, Hato Viejo, Quintoque, Sirigay, Peńa Blanca, Arboledas y El Charco. Posee varias cuencas hidrográficas como la Laguna de Fúquene, el Río Suárez y la quebrada Los Cerezos, además de otras quebradas y gran cantidad de pozos o aljibes, que son utilizados como fuente de abastecimiento de los acueductos $(1,2)$.

Según la Defensoría del Pueblo en el informe realizado en el año 2009 sobre la clasificación municipal de la provisión de agua en Colombia, el municipio de San Miguel de Sema tiene un Índice de Riesgo de Calidad de Agua para Consumo Humano (IRCA) medio de 36, según la clasificación de la Resolución 2115 de 2007, con una prioridad de cobertura alta, ubicándose a nivel departamental en la posición 46 y a nivel Colombia en el $552(1,3)$.

En este municipio el agua de los acueductos veredales no llega a la totalidad de las viviendas; además, algunos colegios no cuentan con agua potable en sus instalaciones y algunas fuentes de abastecimiento de los acueductos presentan contaminación debida a aguas residuales domiciliarias y desechos de residuos sólidos ya que no se cuenta con un sistema de alcantarillado, ni de recolección de basuras en el área rural $(1,3)$.

La vereda El Charco ocupa el 6\% del territorio municipal. Tiene como actividad principal la ganadería, seguido de la siembra de papa, maíz, nabos y árboles frutales como tomate de árbol, curuba, durazno y la crianza de aves de corral. Se localiza en la cuenca hidrográfica del Río Suárez y posee tres acueductos $(1,2,4)$. Entre los acueductos de la vereda, se encuentra el proveniente del aljibe El Pulgarín, llamado acueducto veredal El Charco, conformado por 28 casas y aproximadamente 120 habitantes. Además, se realiza el suministro al Colegio de Educación Básica y Media Técnico El Charco y a la Capilla de la vereda.

\section{Materiales y métodos}

El municipio de San Miguel de Sema se vio afectado por las inundaciones derivadas del fenómeno de La Niña en la temporada 2010-2011, lo que hizo difícil el acceso a la vereda El Charco. Una vez se tuvo acceso a la vereda por vía terrestre se tomaron las muestras en los meses de septiembre y octubre de 2011 (5). Los puntos de toma de muestra del acueducto de la vereda El Charco fueron los siguientes:

1. Nacimiento del Aljibe El Pulgarín.

2. El desarenador ubicado a aproximadamente 20 metros del aljibe.

3. Sitio de cloración, ubicado aproximadamente a 200 metros del desarenador.

4. Grifo del Colegio de Educación Básica y Media Técnico El Charco.

5. Grifo de una casa de la vereda con tanque de almacenamiento domiciliario.

6. Grifo de una casa de la vereda en sin tanque de almacenamiento domiciliario.

Se llevó a cabo la determinación de los indicadores bacterianos con las recomendaciones del Standard Methods for the Examination of Water and Wastewater $(6,7)$, se empleó la técnica de Filtración por Membrana. Para la identificación de los microorganismos se utilizó BBL Crystal.

\section{Resulltados}

En la Tabla 1 se presentan los recuentos obtenidos para los indicadores bacteriológicos usados. 
Tabla 1. Recuento de UFC/100mL de coliformes totales, E. coli y Enterococcus

\begin{tabular}{ccccccc}
\hline & COLIFORMES TOTALES & \multicolumn{2}{c}{ E. coli } & \multicolumn{2}{c}{ Enterococcus } \\
PUNTOS DE MUESTREO & SEPTIEMBRE & OCTUBRE & SEPTIEMBRE & OCTUBRE & SEPTIEMBRE & OCTUBRE \\
\hline $\begin{array}{c}\text { 1. Nacimiento del Aljibe El } \\
\text { Pulgarín }\end{array}$ & 96 & 68 & 0 & 0 & 2 & 54 \\
\hline 2. Desarenador & 48 & 32 & 0 & 0 & 2 & 0 \\
\hline 3. Sitio de cloración & 36 & 26 & 0 & 0 & 0 & 14 \\
\hline 4. Grifo del Colegio & 0 & 0 & 0 & 0 & 0 & 6 \\
\hline 5. Grifo casa con tanque & 2 & 15 & 0 & 0 & 2 & 240 \\
\hline 6. Grifo casa sin tanque & 0 & 0 & 0 & 0 & 0 & 2 \\
\hline
\end{tabular}

En el acueducto de la vereda El Charco se realiza el tratamiento a las aguas, iniciando el paso por un tanque desarenador (punto 2), una filtración por gravedad multicapa (punto 3) y enseguida se realiza la desinfección con cloro, con el objetivo final de destruir los microorganismos presentes en el agua. Las muestras de agua en los puntos 4, 5 y 6 , ya han recibido el tratamiento completo.

En la Figura 1, se observa que las muestras 1, 2, 3 y 5 presentan recuento de coliformes totales, por lo tanto, según la Resolución 2115 del 2007 (8), el agua de estos puntos no es apta para el consumo humano.

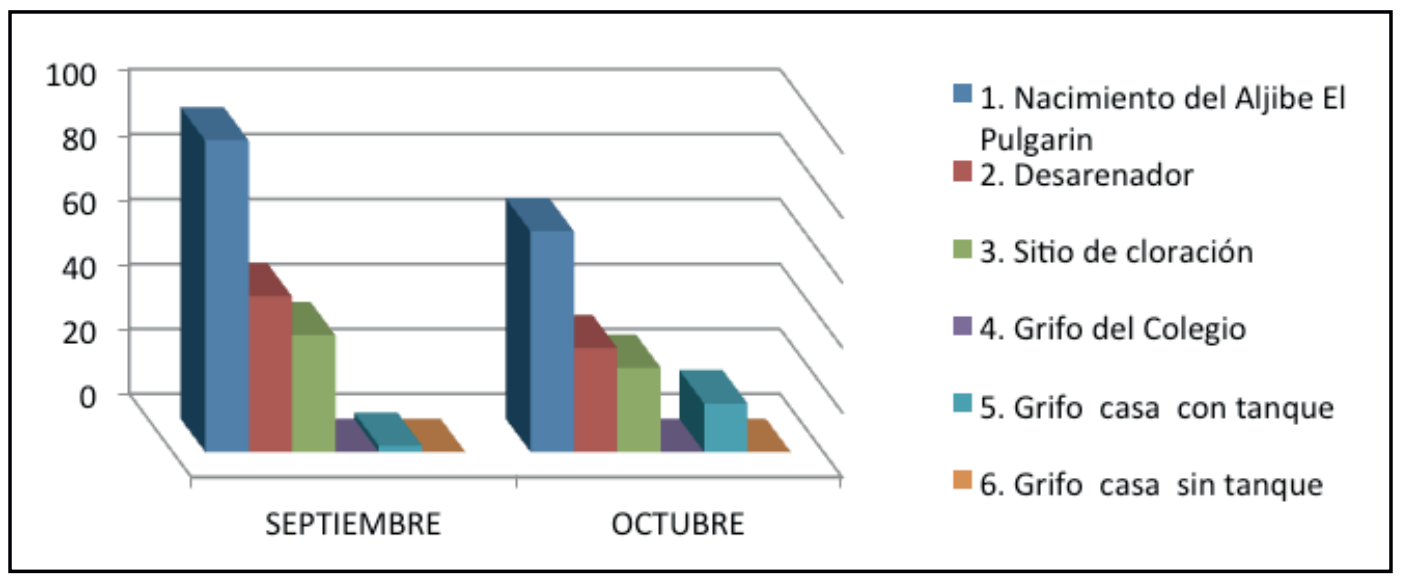

Figura 1. Recuento de UFC/100mL de coliformes totales en los dos meses muestreados

Para el caso de la Escherichia coli, en ninguna de las muestras analizadas se evidenció crecimiento, lo que quiere decir que para este parámetro las muestras analizadas cumplen con lo establecido en la Resolución 2115 de 2007.

Según la NTC 813 de 1994, que evalúa en uno de sus parámetros la presencia de Enterococcus ninguna muestra de agua potable para consumo humano debe presentar crecimiento de microorganismos (9).

En la Figura 2, se observa que, en el mes de septiembre, el agua de los puntos 3, 4 y 6 es apta para el consumo humano, con base en el recuento de Enteroccocus. Los puntos 1, 2 y 5 de este mismo mes y las muestras correspondientes al mes de octubre presentan crecimiento de UFC/100mL, por lo tanto, no es apta para el consumo humano. 


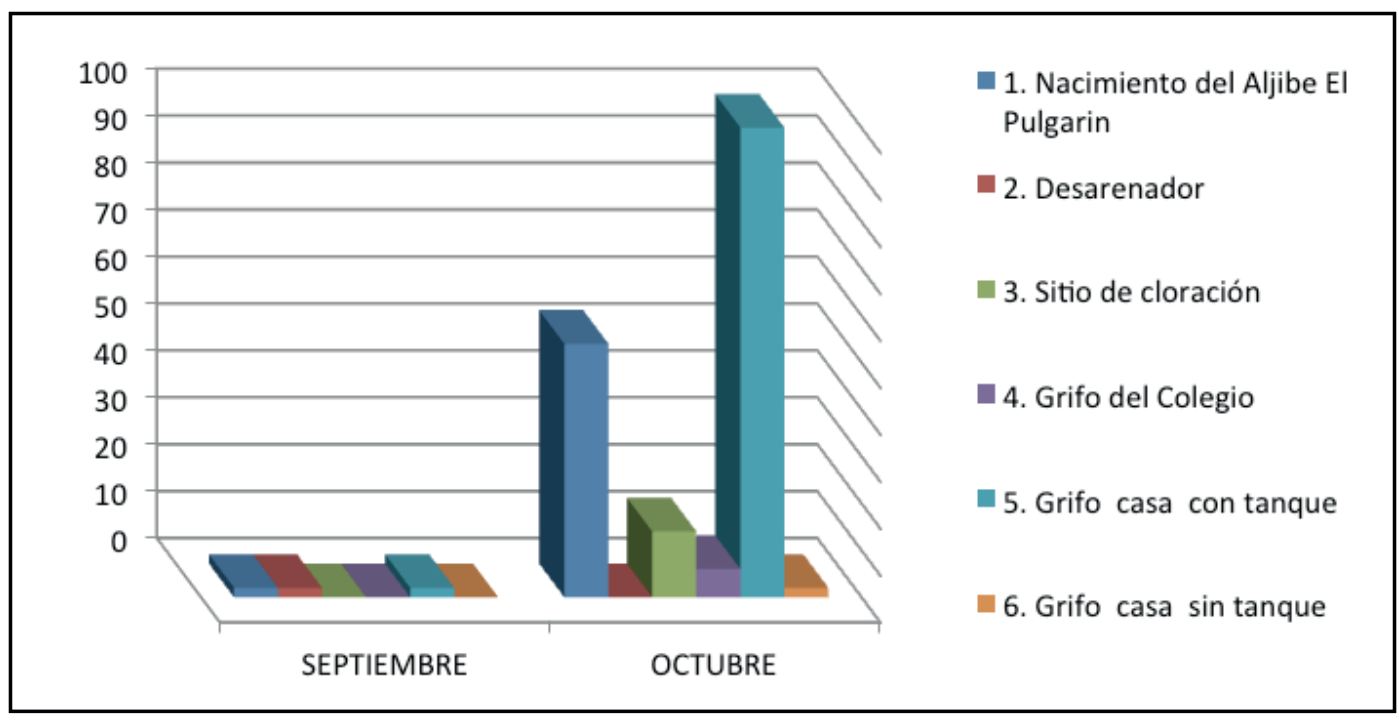

Figura 2. Recuento de UFC/100mL de Enterococcus en los dos meses muestreados

La identificación de los microorganismos aislados en las muestras de agua, se realizó por medio de pruebas bioquímicas rápidas Crystal BBL. Los resultados se presentan en la Tabla 2 .

Tabla 2. Microorganismos aislados en el acueducto veredal El Charco.

\section{P Puntos de muestreo}

1. Nacimiento del Aljibe El Pulgarín

\begin{tabular}{|c|c|}
\hline 2. Desarenador & $\begin{array}{c}\text { Enterobacter cloacae, Enterococcus faecalis, Klebsiella oxytoca, Pseudomonas putida, } \\
\text { Acinetobacter baumannii y Oerskovia species }\end{array}$ \\
\hline 3. Sitio de cloración & $\begin{array}{c}\text { Enterobacter cloacae, Lactococcus lactis ssp lactis, Klebsiella oxytoca, Serratia fonticola, } \\
\text { Acinetobacter baumannii, Kluyvera cryocrescens y Pantoea agglomerans }\end{array}$ \\
\hline 4. Grifo del Colegio & Streptococcus porcinus \\
\hline 5. Grifo casa con tanque & $\begin{array}{l}\text { Pseudomonas fluorescens, Bacillus subtilis, Acinetobacter baumannii, } \\
\text { Lactococcus lactis ssp lactis }\end{array}$ \\
\hline 6. Grifo casa sin tanque & Staphylococcus saprophiticus \\
\hline
\end{tabular}

\section{Discusión}

Según la Resolución 2115 del 2007 y la NTC 813, algunas de las muestras analizadas en el acueducto veredal El Charco del municipio San Miguel de Sema, superan las $0 \mathrm{UFC} / 100 \mathrm{~mL}$ en los indicadores Coliformes totales y Enterococcus, por tal razón no es apta para el consumo humano. Se evidenció 0 UFCl100 $\mathrm{mL}$ de Escherichia coli, esta bacteria al abandonar
Microorganismos aislados

Acinetobacter baumannii, Enterobacter cloacae y Bacillus subtilis Acinetobacter baumannii y Oerskovia species

Staphylococcus saprophiticus el organismo hospedador, disminuye la viabilidad y la capacidad infecciosa gradualmente (10). Otros autores reportan que la Pseudomonas aeruginosa, produce una bacteriocina con acción antibiótica llamada Pseudocin que inhibe el crecimiento de $E$. coli, Enterobacter aerogenes, Citrobacter freundii y Klebsiella sp (10), por lo tanto, debería incluirse la detección de Pseudomonas en agua, ya que en una muestra puede haber ausencia de coliformes debido 
a su inhibición por las Pseudomonas y por esta razón, se considera apta para el consumo humano. Por lo tanto, usar solamente coliformes como indicadores es insuficiente para garantizar el control de la calidad del agua (11). Países como Argentina y Uruguay han incorporado este microorganismo como indicador, debido a su alta diseminación en el medio ambiente y su moderada resistencia a la cloración.

Se debe tener en cuenta que el municipio de San Miguel de Sema, en el año 2011 sufrió una fuerte ola invernal, la Laguna de Fuquene se desbordó y se aumentó la corriente del Río Suárez, lo que provocó una inundación en el 80\% del territorio municipal, contaminando las fuentes hídricas por el agua de escorrentía; por lo tanto, la época en la que se tomaron las muestras influye en los recuentos obtenidos, ya que microorganismos pertenecientes al grupo de los coliformes y Enterococcus son habitantes normales del suelo y su número puede aumentar durante las épocas de lluvia. Al respecto Ávila y Estupiñán, en el estudio realizado en el agua de los humedales Arcial, El Porro, Cintura, Bañó, Pantano Bonito y Charco Pescado, reportaron resultados similares con recuentos altos en época de lluvia entre 20000 y 120000 UFC/100mL debido a la entrada de agua contaminada de otras fuentes como caños y ríos (12). En otro estudio realizado por Cámbara y colaboradores (2010) en la subcuenca del río Quiscab en Guatemala, se encontraron altas concentraciones de coliformes totales y coliformes fecales en época de lluvia, razón por la cual determinaron que el agua no es apta para consumo humano (13).

Los resultados obtenidos en el presente estudio se pueden comparar con el realizado en Argentina, llamado "Contaminación microbiológica en agua de pozo Partido Gral., Pueyrredon. Provincia de Buenos Aires, Argentina." Su objetivo era evaluar el grado de contaminación microbiológica en los barrios, teniendo en cuenta que esta comunidad no cuenta con fuentes de suministro de agua potable; se encontró en el $92.9 \%$ de las muestras coliformes totales (14), el agua es tomada de un pozo y no se le realiza ningún tipo de tratamiento, lo que demuestra que es importante realizar un tratamiento en el agua, ya que se disminuye el nivel de microorganismos.

En otra investigación llamada "Contaminantes Químicos y Bacteriológicos que afectan la calidad de las fuentes de agua de riego en la zona hortícola de San Cosme, Corrientes", siendo el agua analizada utilizada para el riego de cultivos y consumo humano, se determinó la presencia de coliformes totales y fecales, entre otros (15).

El crecimiento de bacterias coliformes totales puede relacionarse con el artículo llamado "Potabilidad del agua de uso doméstico en el estado Nueva Esparta, Venezuela". Este estudio tuvo como objetivo evaluar la potabilidad del agua utilizada para uso doméstico en las Islas Margarita y Coche. Se analizaron 757 muestras divididas así: aguas recibidas desde tierra firme, aguas del subsuelo insular y aguas de la red de distribución a nivel municipal, donde se evaluó la presencia de coliformes totales, coliformes fecales, Escherichia coli, estreptococos fecales y Pseudomonas aeruginosa. De acuerdo a los resultados obtenidos con relación a coliformes totales en los pozos subterráneos, de 13 muestras analizadas, el 62\% presentó crecimiento; en el punto correspondiente a agua tratada con 3 muestras analizadas se obtuvo el 33\% de crecimiento. El estudio concluye que la contaminación indicada por coliformes totales se debe a factores naturales provocados por el hombre y los animales; igualmente está relacionada con la presencia de lluvias que transportan contaminación hacia los pozos, tanto de animales como de humanos, diluyendo nutrientes e incrementando el carbono orgánico (16). Por esta razón es probable que la contaminación que se observó en el aljibe El Pulgarín se asocie con la presencia de contaminantes que pueden llegar al pozo a través de aguas lluvias o se encuentren como flora normal de suelo o el agua. La literatura describe que la humedad es un factor que permite la supervivencia de bacterias entéricas en suelos, sobre todo durante época de lluvia, a esto se suma la disminución de temperatura lo que permite su mayor supervivencia. Con el aumento de lluvias, estas pueden mezclarse con contaminantes que pueden estar sobre el suelo, filtrarse y de esta 
manera llegar a las aguas subterráneas y contaminarlas (17).

En el estudio realizado en el aljibe El Pulgarín, se observa un cambio notable en el recuento de Enterococcus en el punto 5. La muestra se tomó de una casa perteneciente a la red de distribución que cuenta con tanque de almacenamiento domiciliario, presentando 2 UFC/100 mL en el mes de septiembre y 240 UFC/100 mL en el mes de octubre. Es posible que esta muestra presente un recuento alto, ya que si no se realiza periódicamente la limpieza y desinfección de las tuberías y los tanques de almacenamiento domiciliario, se aumenta la presencia de microorganismos indicadores de contaminación fecal antigua. Se ha identificado que las zonas más vulnerables de la red de distribución son los tanques que durante largo tiempo no reciben ningún tipo de limpieza y mantenimiento, convirtiéndose en focos infecciosos de riesgo para la salud (18).

Según un estudio realizado en Nueva Esparta, Venezuela, en donde se tomaron muestras de tanques de almacenamiento, se percibió que 43 muestras (92\%) no tenían el cloro residual recomendado, además hubo crecimiento de Pseudomonas aeruginosa (83\%) y coliformes totales (55\%). En el estudio los tanques de almacenamiento presentaron biopelículas por el estancamiento del agua lo que aumentó el gasto de cloro, por este motivo es necesario tener en cuenta el nivel recomendado de cloro residual libre, ya que si no se cumple la norma se incrementa el crecimiento de microorganismos, además es importante realizar la limpieza periódica (16) según el Decreto 1575 de 2007, que en el artículo 10 establece que cada 6 meses se debe realizar la limpieza de los mismos (19-24).

Los resultados del presente estudio se socializaron con la comunidad de la Vereda El Charco y se brindaron recomendaciones sobre el mantenimiento de los tanques de almacenamiento del agua y los riesgos del consumo de agua contaminada.

\section{Referencias}

1. San Miguel de Sema. Fuente de Paz, Progreso y Encanto de Paisajes. Plan de Desarrollo 2008-2011. Boyacá; 2008.

2. Libio Silva. San Miguel de Sema, Origen, historia y desarrollo. Bogotá D.C. Kapra; 2003.

3. Clasificación Municipal de la provisión de agua en Colombia. Defensoría del Pueblo. Bogotá D.C.; 2009.

4. Diagnostico Plan de Desarrollo 2004-2007. San Miguel de Sema. Boyacá; 2008.

5. ICONTEC. Norma Técnica Colombiana 813, Normas oficiales para la calidad del agua en Colombia. Bogotá, ICONTEC [en línea] [Revisado el 15 de Marzo de 2010]. Disponible en: http://poseidon.unalmed.edu.co/PGA/materias/funda_cont/ docs/normas/agua_potable/colombia

6. Standard Methods for the Examination of Water and Wastewater. Method 9222 B. Standard total coliform membrane filter procedure. 2003. [en línea]. [Revisado el 20 de Junio de 2010]. Disponible en: http://www.epa.gov/OGWDW/disinfection/ lt2/pdfs/guide_lt2_mlmanual_appendix-k.pdf.

7. Standard Methods for the Examination of Water and Wastewater. Method 9222 Membrane Filter technique for members of the coliform group. [en línea], [Revisado el 20 de Junio de 2010]. Disponible en: http://etd.lib.fsu.edu/theses/available/etd-1103 200431319/unrestricted/03_kap_supplement2.pdf.

8. Colombia. Ministerio de Protección Social, Ministerio de Ambiente, Vivienda y Desarrollo Territorial. Resolución 2115 de 2007.por el cual se señalan características, instrumentos básicos y frecuencias del sistema de control y vigilancia para la calidad del agua para consumo humano. Bogotá: El Ministerio; 2007.

9. Colombia. Icontec. Norma Técnica Colombiana 813, establece los requisitos físicos, químicos y microbiológicos que debe cumplir el agua potable. Disponible en: http://www. slideshare.net/jamesdays/texto-ntc-813-agua-potable

10. Organización Mundial de la Salud. Guías para la calidad del agua potable [recurso electrónico]: incluye el primer apéndice. Vol. 1: Recomendaciones. Tercera edición. Disponible en: http://www.who.int/water_sanitation_health/dwq/gdwq3_ es_fulll_lowsres.pdf. 2006

11. Sara Lilia Ávila de Navia, Sandra Mónica Estupiñán Torres. 2013. Calidad Sanitaria Del Agua del Parque natural Chicaque. NOVA. Vol.11 No. 20. Pag 45-51.

12. Ávila de Navia SL, Estupiñán Torres SM. 2010. Evaluación de la calidad microbiológica del agua de los humedales Arcial, el Porro y Cintura (río San Jorge), y los humedales Baño, Pantano Bonito y Charco Pescado (río Sinú) en Colombia Diversidad Biótica IX.

13. Padilla C, García N, Pérez W. Caracterización físico-química y bacteriológica, en dos épocas del año, de la subcuenca del río Quiscab, Guatemala. Revista Ciencias Técnicas Agropecuarias. 2010. 19(3): 43-46. 
14. Zamora A, Folabella A, Pérez Guzzi J, Domínguez S, De Lucha L. Contaminación microbiológica en aguas de pozo. Partido GRAL. Pueyrredon. Provincia de Buenos Aires. Argentina. GAHD. Disponible en: http://www.alhsud.com/ public/articulos/Zamora.pd

15. Ortiz M L, Martínez, G C. Contaminantes Químicos y Bacteriológicos que afectan la calidad de las fuentes de agua de riego en la zona hortícola de San Cosme, Corrientes. UNNE. Disponible en: http://www1.unne.edu.ar/cyt/agrarias/a-021.pdf

16. Iriarte MM, Gómez A. 2008. Potabilidad del agua de uso doméstico en el estado Nueva Esparta, Venezuela. Rev. Inst. Nac. Hig. 39 (2): 23-34.

17. Letterman R. Calidad y tratamiento del agua: manual de suministros de agua contaminada. 5a Edición. España. Mc Graw Hill Interamericana. 2002. p. 176-177.

18. Ministerio de Salud de Argentina. Provincia de San Luis. Limpieza y desinfección de cisternas y tanques de reserva para el agua potable. Laboratorio Control de Alimentos. Disponible en: www.msal.gov.ar/pngcam/resoluciones/msres898_2001.pdf

19. Ministerio de la Protección Social. Decreto 1575 de 2007, por el cual se establece el Sistema para la Protección y Control de la Calidad del Agua para Consumo Humano. Bogotá: el Ministerio. 2007

20. De Navia SLÁ, Torres SME. Calidad sanitaria del agua del Parque Natural Chicaque. Nova. 2013;11.

21. Galvez, Z. Y. A. and V. E. M. Burbano (2015). "Bacillus: género bacteriano que demuestra ser un importante solubilizador de fosfato." NOVA Publicación en Ciencias Biomédicas.

22. Ramírez, L. C. C., et al. (2014). "Determinación de la presencia de bacterias patógenas para el humano en aguas de riego en la cuenca alta de la sabana de Bogotá; DC Colombia." Nova 12.

23. Campuzano, S., et al. (2015). "Determinación de la calidad microbiológica y sanitaria de alimentos preparados vendidos en la vía pública de la ciudad de Bogotá DC.” Nova.

24. Corrales, L. C., et al. (2015). "Bacterias anaerobias: procesos que realizan y contribuyen a la sostenibilidad de la vida en el planeta." Nova 13(24): 55-82. 